\title{
Networking in Spain
}

\section{Miguel Jiménez and Alice Keefer}

Spain is a country whose development level falls in the middle range within the European Community; in fact, when measured for certain industry and infrastructure indicators, it resembles the industrialized countries of the north more than other southern-tier countries. All analyses coincide in showing that Spain has experienced strong growth in the last decade and this also holds true in the area of library services. However, libraries are not at a comparative level with the rest of Europe in terms of funding or services. In general their progress continues to be impeded by a lack of economic and material means, traditional underutilization and the nonexistence in much of the country, until very recently, of library schools or other training programmes which contributed to an ill-prepared corps of professionals. On a positive note, Spanish libraries' late entry into the world of automation has had its advantages, by allowing them to "leap-frog" over the woes of early automation projects and to benefit from the experiences of others and from an everimproving technology. Libraries automating within the past two years have had a greatly expanded market to choose from and have been able to implement their systems much faster than others that began earlier. In some cases, the pioneers in library automation are in the most disadvantaged situation as they are tied to older programmes and technologies. Although Spanish libraries' entry into computerized networks is relatively recent, they are proceeding without the same delays they experienced when automation began in earnest.

\section{Concept of networks}

There are different opinions about the use of the term "library networks", and, in this same journal, the concept at times has been used in a more traditional sense ${ }^{1}$. Dempsey ${ }^{2}$, on the other hand, maintains that physical links are needed when defining networks today:

Miguel Jiménez is Director of Unidad de Coordinación de Bibliotecas, Consejo Superior de Investigaciones Cientificas, Jorge Manrique 27, 28006 Madrid, Spain.

Alice Keefer is Director of International Services, DOC6, Tuset 21, 08006 Barcelona, Spain. 
"An inclination to think in this way [refer to the resource-sharing aspect of networks] was encouraged by the original 'exemplary networks' - the bibliographic utilities, or online hosts. Computer networking was a totally subsumed aspect of larger service organizations. 'Networks' were single purpose and associated with the services they made accessible. As the use of networking becomes pervasive of library activites, as the infrastructure becomes available which makes data transfer much more common, and specially as library services are increasingly delivered to end-users over networks, this identification will become difficult to sustain".

Although the authors agree with Dempsey's view, for the purposes of this article the physical link requirement has been relaxed in order to be able to include projects of computerized union catalogues that currently are linked only via CD-ROM, for if Dempsey's definition were strictly adhered to there would be very few networks in Spain to discuss here.

To conclude this introduction, we would like to state that the varying meanings of "network" have been debated in the professional literature in Spain over the past several years ${ }^{3,4}$.

\section{Recent improvements in library services}

In spite of the economic growth and the development of services and infrastructure that Spain has experienced in the years since Franco's death, especially in the second half of the 1980s, Spanish library services occupy the bottom positions among the countries of the EEC ${ }^{5}$. The situation early on was especially negative within the public libraries and the National Library, while the conditions of university and specialized libraries were closer to Western European standards.

A major decentralization of the Spanish government took place following the democratic constitution of 1979 , with many areas of responsibility among them libraries - passed on to the governments of the 17 Autonomous Communities. This new configuration has favoured the development of public libraries which previously were almost nonexistent except for the Public Libraries of the State (one in each provincial capital) and several systems in Catalunya.

The concession of administrative autonomy to many of the 37 public universities and the growth in the hiring of professional librarians in the 1980s, has made the sector of university libraries the most dynamic of the profession in Spain. Finally, the Ministry of Culture has made considerable investments for the construction and improvement of buildings and for 
acquiring computer equipment for the Public Libraries of the State and the National Library which have contributed to positive changes in these sectors as well.

Regarding library automation, the situation of rapid change has been described in various publications ${ }^{6,7.8,9}$; however, networks have been touched upon only slightly in these sources ${ }^{10}$, due probably to their very recent development. This article is divided into three parts: the first dealing with networks and union catalogues of a general nature; the second, with libraries grouped by area of specialization; and the third discusses two private computerized networks used by Spanish libraries.

\section{Networks of a general nature}

1. Ruedo ${ }^{11,12}$ is a network currently consisting of seven university libraries that have Dobis-Libis software (which runs on IBM mainframes). The impetus to create this network came from the fact that Dobis-Libis is the software used in most installations among Spanish universities. The organizational coordinator - and site of the "host" - is the University of Oviedo. Although financed basically by its own members, the network has received substantial grants from the Interministerial Commission for Science and Technology (CICYT) and the national plan for R\&D.

The union catalogue is accessible using Dobis-Libis software running on an IBM $390120 \mathrm{~J}$ dedicated solely to this task and contains approximately 500,000 records corresponding to 600,000 physical volumes. At the moment, the catalogue is accessible via Iberpac (Spain's X.25 network operated by Telefonica) and via Internet from four of the participating universities: Deusto, Navarra, Oviedo and the University of Distance Education (UNED), and only for purposes of searching. Although to date they have not attempted any bibliographic control or detection of duplicates, these are among the objectives of the network for the immediate future. The catalogue is also expected to serve for ILL. The database is updated by tapes.

In spite of the homogeneity of a network based on the same software, there are problems involved in integrating records due to cataloguing differences among the member libraries.

2. The network of the Superior Council of Scientific Research (CSIC) was begun in November, $1986^{13}$. This research institution which comes under the Ministry of Education and Science, has more than 80 institutes in 20 different cities around the country. Early on, the Aleph software which has been used to automate CSIC's libraries, was loaded on a Cyber (Control Data) computer. In November 1989 a new version of Aleph was installed on Vax equipment from DEC. 


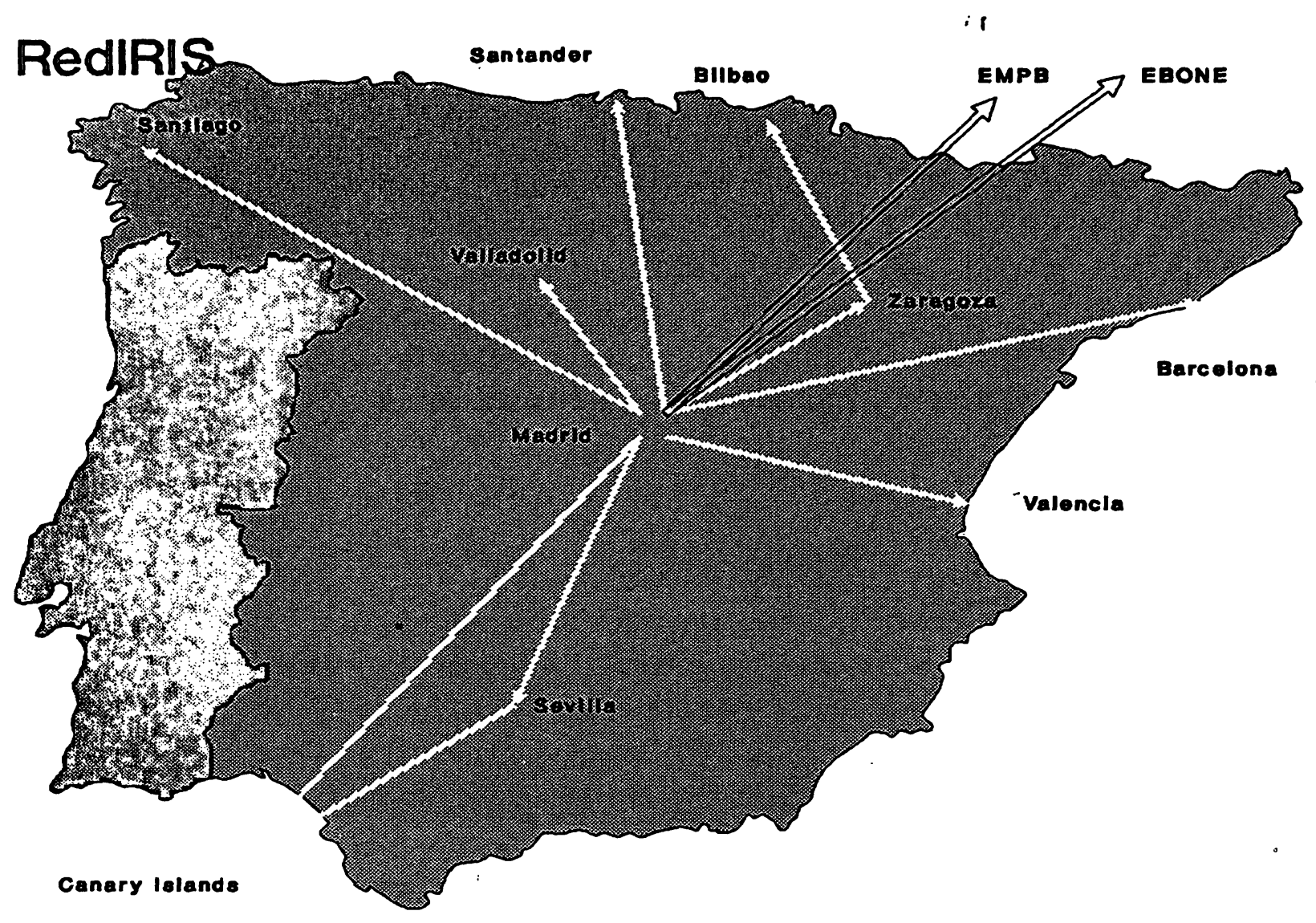

Fig. 1.

Currently there are 78 libraries participating in the network, of which 71 are CSIC's and seven are of other research institutes belonging to private foundations or national academies. The principal node of the network is in Madrid which is the site of the two principal union catalogues: CIRBICLibros with 293,000 bibliographic records of monographs - corresponding to more than 400,000 copies - , and CIRBIC-Revistas, with 35,100 periodical titles. Four regional nodes exist: Sevilla, for libraries within the Autonomous Community of Andalucia; Barcelona, for all of Catalunya; Valencia, for the Communities of Valencia and Murcia; and Vigo, for installations in Galicia. Periodically the central catalogue is updated via magnetic tapes or by file transfer via Decnet. A batch routine is run when the database is updated that includes a programme to detect duplicates. The number of dedicated terminals in the network is 139. However, in the central facilities of CSIC in Madrid, there are a total of 220 terminals, 160 networked PCs and 40 workstations, and each of these could potentially access the union catalogues.

The libraries within the network frequently use E-mail (for ILL, among other things) and can access free of charge CSIC's other bibliographic data- 
bases containing several hundred thousand references to articles published in Spanish scientific journals. These databases reside in the same computer as the above mentioned union catalogues. All the communications take place within Spain's academic network, RedIRIS, that is described in the third section of this article.

One important aspect of this network is its wide reach, since it is accessible via RedIRIS, Internet, X.25 or IXI, and for the past two years on CD-ROM as well ${ }^{14}$. From the technological point of view, two other aspects warrant special mention: the connection between the Sevilla, Barcelona, Valencia and Madrid nodes is transparent for the user and permits alternating a search on the regional catalogue (Sevilla or Valencia) to the union catalogue in Madrid, as well as transfering bibliographic records from one catalogue to another in interactive mode directly from the cataloguing module. The other interesting utility is the existence in the catalogues of records with text in Arabic and Hebrew characters (Greek characters will be introduced in the future as well) and these can be viewed using a VT320/420 terminal.

3. Network of University Libraries (Rebiun) is a consortium of thirteen universities with ambitious plans, among which are the creation of union catalogues and interlibrary loan. It is in this latter area that they have concentrated most of their efforts. However, they do not use computer connections for ILL as yet. Faxes, on the other hand, are regularly employed for transmission of both requests and photocopies of articles.

Recently a CD-ROM ${ }^{15}$ was published containing a union catalogue of the holdings of four of the member institutions, with more than 300,000 Marc monograph records and 29,000 serial titles from an already existing union list, CAPS, based on the holdings of several Catalan institutions (most of which are non-Rebiun members). The disc allows for downloading and editing of tagged Marc records. The monograph catalogue, unlike the serials file, is not weeded for duplicates in this initial version. The disc, to be issued half yearly, is expected to include records from additional institutions in the future, and was due out by the end of 1992 .

The union catalogue cannot yet be consulted via a host; however there are plans for mounting the database in an IBM 3090 at the University of Barcelona. It was this institution that headed up the CD-ROM project and prepared the tapes containing records in Ibermarc, Catmarc and UKMarc (D-Marc records from Dobis-Libis member libraries may be added in the future). Besides integrating records in different Marc formats, the preparation of the data for the CD-ROM also involved reconciling differences caused by the use of different cataloguing standards - AACR2 and the "Reglas de Catalogación" of the Spanish Ministry of Culture.

4. In 1983 the Ministries of Culture and of Education and Science put into 
motion an ambitious and expensive plan to create a National Union Catalogue for Serials Publications. However, the project has only published a section devoted to medical journals ${ }^{16}$ consisting of some 9,000 titles. The data for the general catalogue, containing some 100,000 titles with holdings information, were taken in ISBD(S) format from 1,700 libraries. The records that correspond to serials with ISSNs (some 50,000 titles) are available through a host at the National Library, the institution that has overseen the project in recent years. The publication of this database on CD-ROM has been expected for some time now.

Unfortunately, when finally published, the information from a large number of centres will be almost a decade old. The unhappy history of this project should serve as a warning against undertaking projects on such a major scale without prior experience in this type of collective exercise.

5. This past year the Union Catalogue of Bibliographic Patrimony (Pabi) was transferred from the National Library to the National Center for Library Coordination within the Ministry of Culture. Currently approximately 98,000 works have been entered, corresponding to some 140,000 copies, out of a total of 1,000,000-2,000,000 old books that exist in Spain's public and private libraries. The records, in Marc format, are accessible via the "PIC" service on the host computer in the Ministry of Culture. The Catalogue is being financed by the Ministry and the councils of 11 of the Autonomous Communities. The possibility of speeding up the process in the future by using a brief bibliographic description is being studied, especially in light of the fact that the Law of Patrimony (Law 16/1985) sets a deadline for carrying out inventories.

6. The Ministry of Culture possesses the buildings and bibliographic collections of the 51 Public Libraries of the State, which exist in each of the provincial capitals. It is also responsible for their automation ${ }^{17,}{ }^{18}$. This process was first begun using Dobis-Libis and, more recently, Absys/BRS. In all, there are some 30 libraries that have been automated with a total of 386 dedicated terminals. This ambitious plan establishes the National Library as the head of the entire system and expects to have automated all 51 libraries by 1994 .

The union catalogue (Proin), which resides on a host computer in the Ministry's Center for Library Coordination, is updated by tape and is not yet accessible for remote connection due to the cost of telecommunications. This catalogue is used for shared cataloguing by means of tapes sent to the libraries. The major problems arise from the use of two different automated systems and from the difficulties faced by some library personnel in working with the complex Ibermarc format.

7. Sicab is the Information System of Automated Library Catalogues 
which was developed by the Department of Culture of the Generalitat of Catalunya (Autonomous Government) for bibliographic searching and shared cataloguing. Twenty-one libraries now participate by introducing cataloguing data and another seventeen connect online for searching. The system houses several databases, including those of the National Bibliography of Catalunya; the National Library of Catalunya; the union catalogue of the Generalitat's public library network; the two union catalogues of bibliographic patrimony (15th-18th century; 19th century); union catalogues of sports and archives; as well as other individual collections. In all the system contains 227,000 bibliographic records as well as a directory of libraries and a list of subject headings in Catalan.

Sicab was developed with Basis software and resides on an IBM 3090 in the Generalitat running on the VM/XA operating system. Online access to the system is possible via X.25, X.28 or videotext connections. To date there are 115 terminals, 20 PCs and 30 printers connected to the network.

In addition to the searching and cataloguing features, an acquisition module was completed in November 1992, and a serials module is being tested with release expected for the first quarter of 1993. Fax and E-mail are also supported.

8. The Public Library Network of the Diputació (Provincial Government) of Barcelona began its automation project in 1989 with the installation of Spain's first VTLS system. The union catalogue of the 102-library network is maintained on an HP 3000/967, with cataloguing done by a central office. Libraries outside of the city of Barcelona have HP3000 917LX machines. There are presently some 59,000 bibliographic records as well as 45,000 authorities records loaded. Automation of all of the libraries will be implemented in stages; to date seven libraries have been connected to the network with another two expected by the end of 1992.

The connections between the central cataloguing office and the host are via Ethernet using fibre optics. External communications are by X.25. Information is transferred via X.25 as well as by magnetic tapes. There are currently 77 dedicated terminals connected to the network, which also serves for local lending among participating libraries. Acquisitions and serials control via the network will be introduced in 1993.

The Libraries of the Diputació also form a part of the newly created VTLS network, discussed in a following section.

9. In the Basque province of Guipuzcoa, 17 public libraries are taking part in an experiment using E-mail made possible with the services and economic support of the Spritel network (described later in this article). The experiment, Bibliocor, was organised by the Association of Librarians and Documentalists of Guipuzcoa, with PCs, modems and telecommunications costs 
being financed by Spritel. Although 50 libraries were initially expected to participate, the reticence of some local authorities has reduced the number of institutions that are actually involved. In spite of difficulties, it is a truly pioneer experience in Spain where the public library sector is especially backward in the use of information technology in general, and in networking in particular.

The E-mail in this project has been used for creating local bibliographies and, to a lesser degree, for ILL transactions.

10. Sibi is, as of this writing, a project still in the planning phases within the Ministry of Education's Secretariat of State for Universities and Research (SEUI). Under this Ministry come the universities (although with a certain level of autonomy), national academies and the Superior Council of Scientific Research (CSIC). In 1988 SEUI commissioned a quasi-governmental foundation to prepare a report on the creation of an automated network that would unite all existing automated systems of those libraries coming under the Ministry's authority ${ }^{19}$. In 1989, an independent expert was asked to make a critical evaluation of the proposals set forth in the previous year's report. The result was the rejection of the foundation's recommendations (a centralized host accessed by remote connection from the libraries) and the preparation of another proposal ${ }^{20,21}$ that was technically quite different from the first: a union catalogue based on the use of relational and distributed databases. The model for this technical solution met with serious resistance, especially on the part of members of existing networks who tended to support the first report. However, the proposals of the second report were finally firmed up in the paper prepared by a working group made up of experts from SEUI, CICYT, National Library, Rebiun, CSIC, Ruedo and several individual universities.

11. The primary objective of the new network formed by VTLS users is to link the OPACs of the member libraries for cooperative cataloguing and ILL. The founding members were the Diputació de Barcelona (mentioned above) and three Catalan universities: Autònoma de Barcelona, Politècnica de Catalunya and the Pompeu Fabra. Several other institutions which have recently acquired VTLS, including three new universities, are also expected to join this network. Although supported by member contributions, additional funds have been obtained from regional and national government agencies for specific projects as well.

The first phase of the project - linking member libraries - was accomplished in May, 1992. The second phase - creation of a central database - is expected to be implemented in 1993. The physical network used is RedIRIS (discussed below), using X.25 protocols. The current members all have HP 3000 computers. 
The combined databases contain 508,000 bibliographic records corresponding to 777,000 actual items with holdings, all in Catmarc format. Members can consult one another's catalogues without exiting from their local library programme; desired records can be downloaded to the local catalogue. Two of the nodes are interconnected to one another by $64 \mathrm{Kbps}$ lines, whereas the other two have slower 9,600 bps lines. Non-members, both institutions and individuals, can consult the OPACs by dialling in through X.25 or through RedIRIS or Internet.

\section{Networks of a subject nature}

1. The Biomedical Documentation Coordinator is a group that was founded in 1983, with no official institutional backing, to coordinate and rationalize the efforts of biomedical libraries and document centres. At present 78 institutions contribute to a database of serials holdings, the Coordinator's principal product. Since 1991, the Coordinator has been subsidized by the Generalitat of Catalunya's Department of Health and Social Security.

The database was developed using Basis software and resides on a Vax $11 / 8350$ at the Statistical Institute of Catalunya (IEC). It now contains 11,700 periodical titles which represent 22,000 serials collections. The catalogue is updated annually with corrections introduced by the central office at the IEC with information provided on paper by the participating members. The decision to have modifications done directly by the members via online connections has been postponed, due to technical problems.

Access to this database is possible via X.25 links to the IEC's host computer which houses other databases as well. A CD-ROM containing the serials catalogue is being planned for 1993.

2. Documat ${ }^{22}$ is a network that began functioning in 1988 involving Departments of Mathematics from Spanish universities together with the CSIC. The network has three objectives: to maintain a union catalogue of serials; to use the catalogue as a means of fulfilling requests for periodical articles; and to avoid, as far as possible, duplicating subscriptions.

Documat's union catalogue of serials now has 2,287 titles corresponding to 6,558 collections in 61 libraries. It resides in the same host as CSIC's other databases mentioned earlier and is likewise accessible online for searching and updating by any library within the network, requiring only a terminal and communications facilities. Approximately $90 \%$ of the requests that go through the network can be fulfilled using the collections of other Spanish institutions, mainly those of the network. Subscriptions to new journals are discussed cooperatively in order to economize on resources. The libraries 
which belong to the Documat network have received some subsidies from CICYT for acquisitions purposes.

3. Redial (European Network of Documentation and Information on Latin America) groups together libraries and documentation centres with collections dealing with Latin American from Spain, France, Holland, etc. There are several automated projects underway, but this article will only address Spain's projects: The catalogue of doctoral theses on Latin America presented at European universities is now printed, as well as included in the CD-ROM "Bibliotecas sin fronteras" discussed later, thanks to assistance from the State Society for the Celebration of the Quincentenary. It contains some 3,400 references. The network has decided to adopt MicroIsis software (offered free of charge by Unesco) in order to facilitate its transportability to Latin America. Unfortunately, there have been problems in converting the information from one format to the other.

In another project, an automated directory of non-governmental organizations with documental holdings on Latin America was created and distributed on diskettes. Neither this product, nor the one containing theses, will be available online.

A third project, the union list of serials on Latin America, had a more unfortunate beginning: for several years it was coordinated by a library that had not fully considered the scope of the project in terms of its own human and technical resources. At any rate, the project is currently in progress and aims to integrate CSIC's serials catalogue (already in magnetic form) with records from NGO Iepala and the Spanish Agency for International Cooperation (AECI).

4. Funded partially by the same State Society for the Quincentenary, a $\mathrm{CD}-\mathrm{ROM}$ has been published ${ }^{23}$ containing a union catalogue of books on Latin America from six libraries: the National Library, Madrid's Universidad Complutense History Faculty, Spanish Agency for International Cooperation, the Gabriel Miro Library (Alicante), the non-governmental Institute for Political Studies on Latin America and Africa (IEPALA) and the CSIC Institute for Latin American Studies located in Seville.

The disc, the first in a series entitled "Bibliotecas sin fronteras" ("Libraries without frontiers"), contains some 250,000 records. The conversion of the different libraries' collections was carried out by different keying services; the merging of records, including detection of duplicates, is being done by the German company, Software AG, who is also automating the National Library. The project's principal dilemma is that the continuation of funding is not assured once the State Society, which has been sponsoring it, is disbanded at the end of 1992. Other problems have been that the libraries were not aware of the true extent of their own holdings; the lack of knowledge of 
the Marc format; and, finally, a certain distrust of the efforts and effects of cooperation on the part of several of the institutions involved, as detected by the project's coordinators.

\section{Computerized networks}

1. RedIRIS is the Spanish academic network financed, more heavily in its first three years (1989/91), by the National R\&D Plan. Through RedIRIS, state universities, CSIC and other public research centres can communicate with one another. It is connected with other European academic networks (Janet, Surfnet, etc.) via the IXI backbone service financed by the EEC's Cosine project EMBP and whose Spanish segment is called Artix. It is also connected with the Internet and EBONE.

The services ${ }^{24}$ which RedIRIS currently offers are E-mail (RFC822), X.500 (pilot) directory, FTAM (pilot) and FTP, and Telnet.

Although Spanish libraries do not constitute a formal group within RedIRIS (as do their British counterparts in Janet), many of those that have the technical means do make use of this network. As to the usage by the general networks described earlier in this article, CSIC and VTLS networks are regular users and Ruedo and Rebiun expect to begin using it in the near future. A directory of the OPAC's currently available through RedIRIS, including 10 catalogues, has been published recently ${ }^{25}$.

2. Spritel is a network financed by the plan for industrial conversion of the Basque autonomous government. Its main objective is to facilitate access to different producers' and distributors' databases by offering the client a single contract. This service also offers equipment, electronic mail and a gateway to RedIRIS. Its Basque users receive grants to cover the telecommunications costs. As was mentioned earlier, some public libraries in the Basque region are using Spritel experimentally in an E-mail project.

\section{Conclusions}

The Spanish panorama for networking offers a number of initiatives at different levels. Some of them are clearly consolidated, such as Ruedo, VTLS and CSIC networks or Documat in the academic and research sector, or the other Catalan networks. Others appear to have a clear future, although at this moment they still lack stable online connections (Rebiun, Public Libraries of the State, or the union catalogues administered by the National Library); while others may never coalesce. Finally, there are others planned on an ambitious scale, like Sibi, but whose funding is not clear.

Among the obstacles to a more rapid growth in networks are: the slow 
pace of adopting changes in the public sector, the technological time lag of many Spanish institutions in comparison with their northern neighbours, the lack of cooperative tradition in Spanish libraries, and the limited technical background of library professionals.

It can be stated that, in comparing Spain to other EEC countries, the Spanish model is more similar to the situation in Britain ${ }^{26}$, Belgium $^{27}$ or France $^{28}$, rather than the more centralized Dutch Pica system ${ }^{29}$ or the Danish $\mathrm{Alba}^{30}$. In Spain, there are two projects which aspire to a high degree of centralization: Sibi, which was discussed earlier, and the Spanish Library System, whose creation was approved by a decree on 19 May 1989. However, in spite of the time lapsed since these were first set forward, their actual functioning still remains a remote promise.

\section{References}

1. Deschamps, Christine: "Cooperation and networking between French libraries". Libri, 41, 4 (1991): 262-271.

2. Dempsey, Lorcan: Libraries, networks and OSI: a review, with a report on North American developments (Bath, 1991).

3. Varela, Concha et al.: "Redes de bibliotecas". Boletin de la ANABAD, 1-2 (1988): 215-241.

4. Becedas, Margarita: "Bibliotecas universitarias: centralización y diversificación internas; cooperación y redes". In Seminario hispano-británico sobre cooperación e informatización de bibliotecas: Madrid, 12-15, marzo, 1990 (Madrid, 1991): pp. 163-178.

5. Ramsdale, Ph: A study of library economics in the European communities (LIB-ECON) (Luxembourg, 1988).

6. Keefer, Alice and Jiménez, Miguel: "Library automation in Spain: an overview". Program, 26, 3 (1992), pp. 225-237.

7. Estado actual de la aplicación de las nuevas tecnologías de la información en las bibliotecas y su impacto sobre el funcionamiento bibliotecario: puesta al día (LIB-2/13-update) (Madrid, 1992).

8. Estivill, Assumpció: “Automation of university libraries in Spain: a status report". In Seminar on innovative information services and information handling (Tilburg: 1992) pp. 91-122.

9. Situación de las bibliotecas universitarias (dependientes del MEC) (Madrid, 1988).

10. Jiménez, Miguel: "Redes bibliotecarias en España y su automatización". In Terceras Jornadas Españolas de Documentación Automatizada (Palma de Mallorca, 1990) pp. 248-267.

11. Rodríguez, Ramón: "The Spanish Dobis-Libis network of libraries". Newsletter of the Dobis-Libis users group, 8 (1990): 9-12.

12. Rodríguez, Ramón: “The present state of the Spanish Dobis-Libis library network". Newsletter of the Dobis-Libis users group, 9 (1991).

13. Ponsati, Agnès: "Les biblioteques del CSIC: una xarxa nacional informatitzada". Item, 8 (1991): 31-42.

14. Bases de datos del CSIC (CD-ROM published by "Micronet" and "La ley").

15. Rebiun (CD-ROM published by "DOC6").

16. Catálogo colectivo nacional de publicaciones periódicas. Medicina (Madrid, 1988). 
17. Moya, Félix and Hípola, Pedro: "La mecanización de la red de Bibliotecas Públicas del Estado". Boletín de la ANABAD, 2 (1991): 119-132.

18. Amador, María José and Catalán, Rosa: "Bases de datos de las Bibliotecas Públicas del Estado". In Tecnimap 91 (Valencia, 1991) pp. 53-59.

19. Normalización e informatización de las bibliotecas científicas españolas (Madrid, 1989).

20. Sistemas de información de bibliotecas cientificas interconectadas y abiertas: SIBI (Madrid, 1990).

21. Cano, Francisco and Costilla, Carmen: "Interconexión de bibliotecas: proyecto SIBI". Iris, 9-10 (1990): 41-44.

22. Oliver, Victoria: "Red Documat: primeros desarrollos y experiencias". In Terceras Jornadas Españolas de Documentación Automatizada (Palma de Mallorca, 1990) pp. 1018-1034.

23. Bibliotecas sin fronteras (CD-ROM published by Chadwyck Healey).

24. RedIRIS, 20-21 (1992).

25. Catálogos de bibliotecas accesibles en línea: directorio (Madrid, 1993).

26. State of the art of the application of new information technologies in libraries and their impact on library functions: a reassessment (LIM-2/1-update) (London, 1991).

27. State of the art of the application of new information technologies in libraries and their impact on library functions: a reassessment (LIB-2/7-update) (Antwerpen, 1991).

28. Etat de l'art et impact des nouvelles technologies de l'information appliquées aux bibliothèques et à leur différents fonctions (Lyon, 1991).

29. State of the art of the application of new information technologies in libraries and their impact on library functions: a reassessment, The Netherlands (The Hague, 1991).

30. State of the art of the application of new information technologies in libraries and their impact on library functions: a reassessment study (LIB-2/4-update) (Copenhagen, 1991). 